\title{
An Inquiry Teaching Mode Based on STEM Education
}

\author{
https://doi.org/10.3991/ijet.v14i17.11204 \\ Lian Zhai \\ Sichuan Vocational and Technical College, Suining, China \\ lydia19811@163.com
}

\begin{abstract}
The course of college English plays an important role in overall improving students' comprehensive quality. Under traditional teaching mode, English teaching is dominated by the teacher, and supplemented by students. Such the efficiency of teaching method is low so that students cannot give full play to their dominant role in learning. Besides, their learning ability cannot improve, and it is difficult to carry out teaching activities efficiently. On this basis, an inquiry teaching mode based on STEM educational concept was explored for the course of college English in this study by combining specific implementation requirements of inquiry learning method. Meanwhile, the teaching effects of experimental class and control class for which traditional teaching mode was applied were compared. The result shows that the inquiry teaching mode based on STEM educational concept has obvious advantages in college English teaching and can significantly improve students' comprehensive ability and professional quality, so it deserves to be referenced for teaching mode reform.
\end{abstract}

Keywords-STEM education; inquiry learning; English teaching

\section{Introduction}

As an important teaching course, college English bears an important basic role for overall promoting students' comprehensive qualities. However, influenced by traditional teaching mode, the teaching process is dominated by the teacher, and supplemented by students. The traditional teaching method is single and rigid, without flexibility. Students fail to give play to their leading role in learning. Their learning ability cannot improve, and the teaching activities are hard to implement. Especially for some students in higher vocational and technical colleges, due to the poor English foundation, there are large difficulties in comprehensive English teaching, which is adverse to teaching mode reform [1]. As the era of "internet +" comes, people start to study various advanced technical means so as to facilitate the integration of relevant educational ideas and STEM education, cultivate students' open and innovation awareness, interdisciplinary innovation and diversified creative thinking abilities, and keep driving deep integration of relevant techniques and teaching. At present, college English teaching urgently needs to accelerate reform, fully refer to the studies of educational theories which emerge with "internet +", and speed up teaching reform of college English course. How to develop a teaching system suitable for college English 
based on the brand-new teaching concept, enhance combination of college English teaching process and students' autonomous learning, and establish a complete and dynamic scheme for the course teaching system becomes a hot direction of the study.

As educational theory of cultivating students' comprehensive ability, STEM education is more and more widely applied in basic education [2]. The effective combination of STEM education with college English course can achieve inquiry learning in real situations, and let students enhance targeted special learning under various situations and well adapt language study and application requirements. So, it is a new inquiry learning mode of college English course. At present, the researches about the application of STEM educational theory in English and other language courses are few, and there is lack of practical teaching experience for reference. This study combines inquiry learning method, and creatively establishes an inquiry learning mode which conforms to the course demand under the guidance of STEM educational theory. This method can improve students' English learning ability and carries important practical significance for cultivating students' special English learning quality. Meanwhile, this study as teaching mode reform for college English can provide feasible reference cases for language course teaching reform practice.

\section{State of the Art}

STEM education originates from American scientific literacy concept, and refers to Science, Technology, Engineering and Mathematics, which stresses crossing and integration of multiple disciplines [3]. Currently, foreign researches on STEM education mostly focus on theoretical research and STEM educational practice exploration. Kelley \& Knowles proposed the pyramid model of STEM course integration. Governments at all levels, organizations and schools in US actively promote STEM research and practice, and the practice in STEM education field mostly starts from such aspect of STEM curriculum resource construction and STEM project development [4]. In the report of "shaping the future: undergraduate education of perspective science, mathematics, mathematics and technology", NSF indicated that, to meet highlevel talent training demand, governments, schools and social organizations should enhance STM\&T teacher training and reach the purpose of national core competitiveness [5]. In order to cultivate undergraduates' engineering quality, Texas A\&M University set up "design-based" scientific research team, emphasized cooperation among students and adopted STEM interdisciplinary knowledge to encourage students to solve engineering problems [6]. Cavlazoglu et al. [7] integrated STEM education in engineering teaching. The researchers utilized the improved Delphi research design to create a key concept list and chain charts containing 35 key concepts. The research results verify STEM education contributes to improving teachers' teaching result. Xie et al. [8] combined theoretical research of physics education to develop the general teaching mode of physics under STEM field based on course features of scientific education and school's current situation of teaching. The mode facilitates STEM quality formation through enhancing the dominant role of students in the learning process. Zhao et al. [9] combined Maker Education and STEM education to estab- 
lish Maker-STEM education based on constructivism and innovation theory which becomes a new education paradigm in the 21 st century. Zhao et al. [10] indicated that STEM owns strong education color of science and engineering and added "art or humane studies" in STEM to form STEAM. Some express that STEM education not just integrates the four courses, but also integrates agriculture, environment and medicine to form a uniform entirety [4].

Influenced by traditional education for many years, college English education as one of important teaching courses is dominated by cramming teaching. Classroom Teaching is basically limited to imparting English knowledge and skill, and ignores training of learning ability, which strikes a serious blow at students' English learning interest [11]. The teaching mode is single, and lacks innovation. Especially for English teaching in some higher vocational colleges, the teaching method also lags behind and cannot meet current development form. In addition, this is also adverse to improving students' comprehensive abilities. Meanwhile, it fails to combine the specific vocational education. As a result, English teaching breaks away from actual need and cannot satisfy requirements of higher vocational education.

Based on the above previous researches, a new teaching tool was innovatively applied in this study, that is, courseware making technology of real situation animation starts to be applied in teaching. This tool can achieve open insertion of real situation, define the content attributes of scene, figure, action and language based on the situation elements, and effectively help implement situational teaching of classroom teaching. Such teaching technology is applicable to classroom teaching of language disciplinary knowledge such as college English. In addition, this study innovatively combined STEM education with inquiry teaching mode in classroom practice of college English teaching, and investigated efficient classroom teaching mode reform for college English with the help of courseware of real situation animation.

\section{Specific Mode of Inquiry Teaching Mode Based in STEM in English Teaching}

\subsection{STEM education}

The core of STEM education is that the teaching contents of the four subjects are closely connected, which requires teaching is implemented in an integral teaching way. Besides, students are required to flexibly apply knowledge and skills to solve the problems in the real world [12]. This theory advocates "design-based, problemsolving and inquiry" learning method, and its essence is to integrate STEM subjects into a whole. The famous STEM pyramid model (as shown in Fig.1) illustrates the integrality feature of STEM subject integration. 


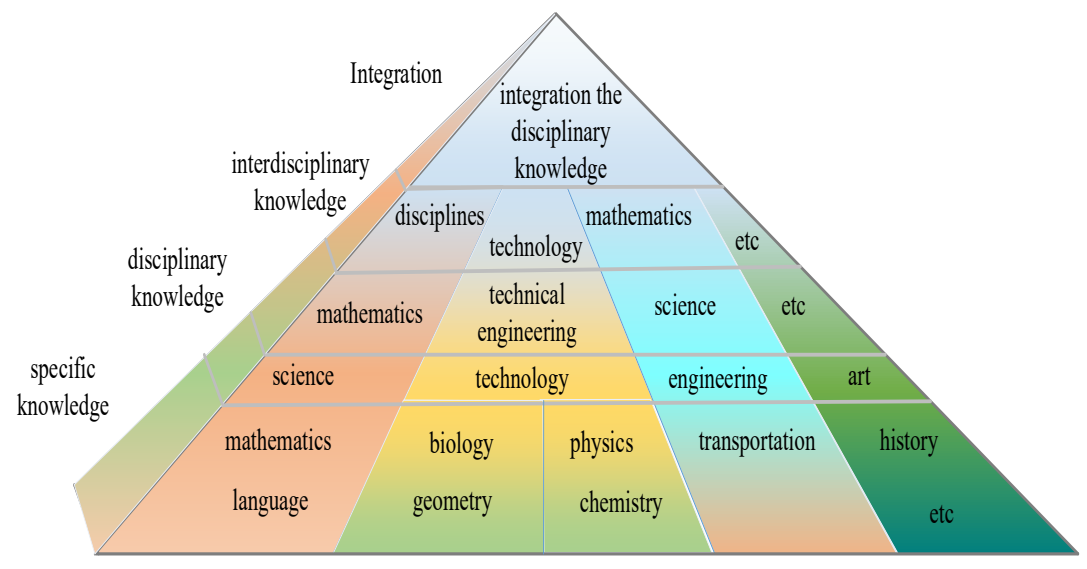

Fig. 1. STEM pyramid model

The model vividly reflects that STEM teaching mode should fully embody the attribute of multidisciplinary knowledge crossing and integration. From the bottom knowledge of various subjects, various subjects are integrated to form the knowledge systems of science, engineering and technology, and the all-round application system of disciplinary knowledge forms through further integration. Finally, a course covering four subjects forms through all-round integration and all-system association, including science and technology, engineering, mathematics and language knowledge. In the end, the basic ability elements which can help solve the problems in the real world form.

In the teaching mode, to refer to the pyramid model, the primary task is to integrate the items of each subject and further develop relevant implementation links on this basis. Take college English course for example. Under the guidance of STEM education, the teaching mode design of this course should fully aim at the teaching tasks. The design content of specific links is shown in Fig.2. For instance, for the design of tool and resource link, rich network teaching resources can be fully utilized, and scene animation making software (such as courseware making technology of real situation animation introduced above), google, Baidu and other information search technologies are used to prepare teaching tools and resources. For learning activity design, special design can be conducted for work division for students groups, inquiry problems and cooperation mode among team members according to the features of teaching content and students' situation analysis as well as task or project demand. In one word, detailed design can be performed as per the requirements in Fig.2. After each link design is completed, the exercise for knowledge enhancement should continue to be enhanced after the implementation of teaching, that is, further exercise through inquiry-based learning problems or tasks, and drive the practice link of teaching mode through teaching application. Meanwhile, the teaching design should be further revised according to practice effect evaluation and feedback. 


\begin{tabular}{|c|c|c|}
\hline \multicolumn{3}{|c|}{ College English teaching mode } \\
\hline \multicolumn{3}{|c|}{ teaching situation analysis } \\
\hline \multicolumn{2}{|c|}{$\begin{array}{l}\text { Tools resources } \\
\text { learning resources and cases } \\
\text { animated situational courseware } \\
\text { information search tools }\end{array}$} & $\begin{array}{l}\text { learning activity design } \\
\text { group division } \\
\text { inquiry problem design } \\
\text { collaboration mode design } \\
\text { experiment plan design }\end{array}$ \\
\hline \multicolumn{2}{|c|}{$\begin{array}{l}\text { Support } \\
\text { program support } \\
\text { control point design } \\
\text { common problem } \\
\text { Feedback } \\
\end{array}$} & $\begin{array}{l}\text { evaluation design } \\
\text { evaluation model } \\
\text { evaluation scale } \\
\text { diagnostic test }\end{array}$ \\
\hline \multirow{3}{*}{$\begin{array}{l}\text { design } \\
\text { revision }\end{array}$} & \multicolumn{2}{|c|}{ inquiry questions } \\
\hline & \multicolumn{2}{|c|}{ project teaching application } \\
\hline & \multicolumn{2}{|c|}{ summary analysis } \\
\hline
\end{tabular}

Fig. 2. Inquiry learning mode design based on STEM

\subsection{Teaching mode combining inquiry teaching mode}

Inquiry teaching generally refers to "learning in practicing". When students are learning abstract concepts and principles, teachers let students automatically discover and explore through reading, thinking, experiment, observation and discussion through concrete examples and questions so that students can grasp the knowledge that have learned. In this process, students can consciously and actively explore relevant knowledge, grasp the methods and steps to cognize things and solve problems, discover internal connection in event development process, seek rule and form concepts in accordance with the attributes of objective things, and establish the personal cognitive model and learning method structure. In other words, inquiry teaching process pays sufficient attention to students' dominant role so that students' learning initiative is enhanced.

Take college English course for example. The necessary media teaching software is adopted, the situation animation making software is combined. In the teaching mode, the inquiry teaching generally follows the process shown in Fig.3. It can be seen that, as the teaching subject, the teacher gives a role of setting up the platform in the inquiry learning. The teacher guides students' desire for independent inquiry through creating English situations. Besides, the teacher explores students' potential of independent inquiry through promoting open classroom. Students participate actively for the purpose of learning problem or task, carry out discussion and construct the knowledge system through group learning. Then, the teacher further guides students, motivates them to learn actively and promotes their application expansion ability through arrange innovation assignments. 


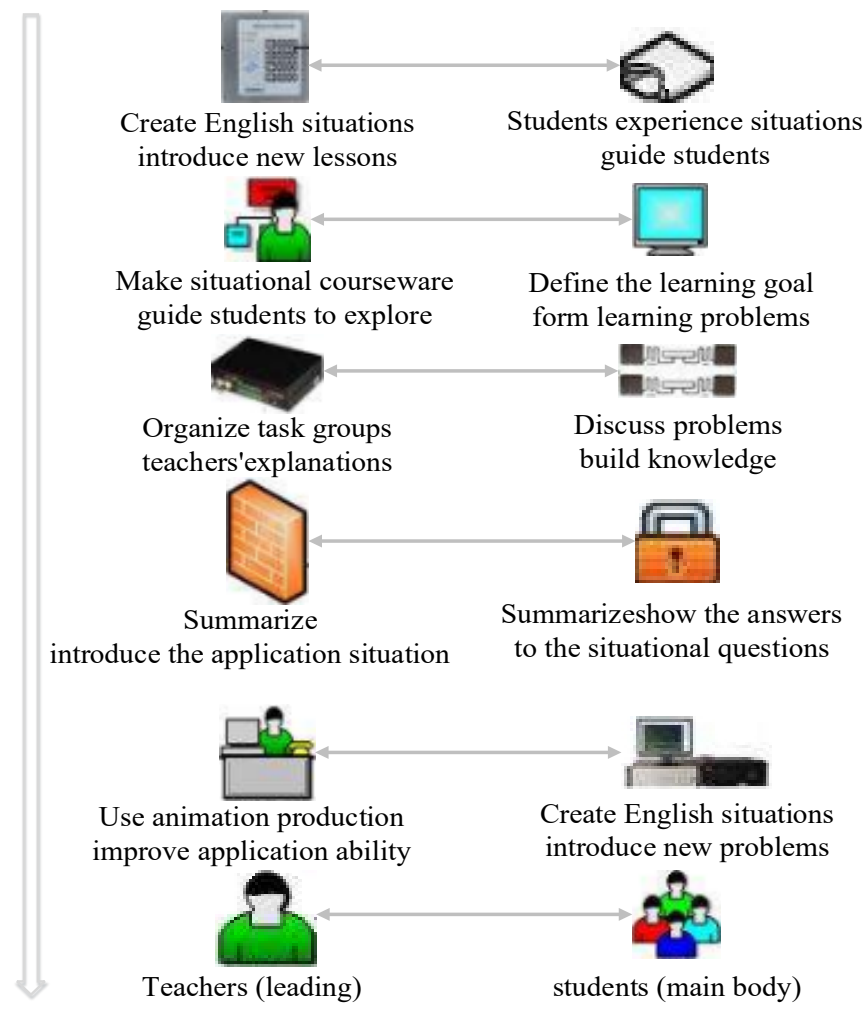

Fig. 3. Inquiry learning mode

Wherein, the situation animation courseware setting should be based on the basic content of teaching content to form animation courseware, like dialogue, situation and occasion. The courseware production can follow Fig4.

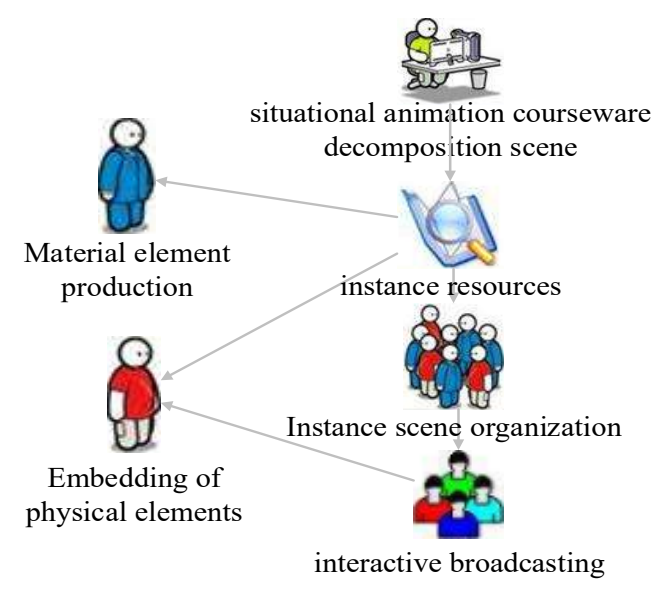

Fig. 4. Design of situation animation courseware making 


\subsection{Inquiry teaching mode based on STEM education}

Based on the above introduction, the inquiry teaching mode based on STEM education is constructed under the guidance of STEM educational theory. The teaching process that this study follows is shown in Fig.5.

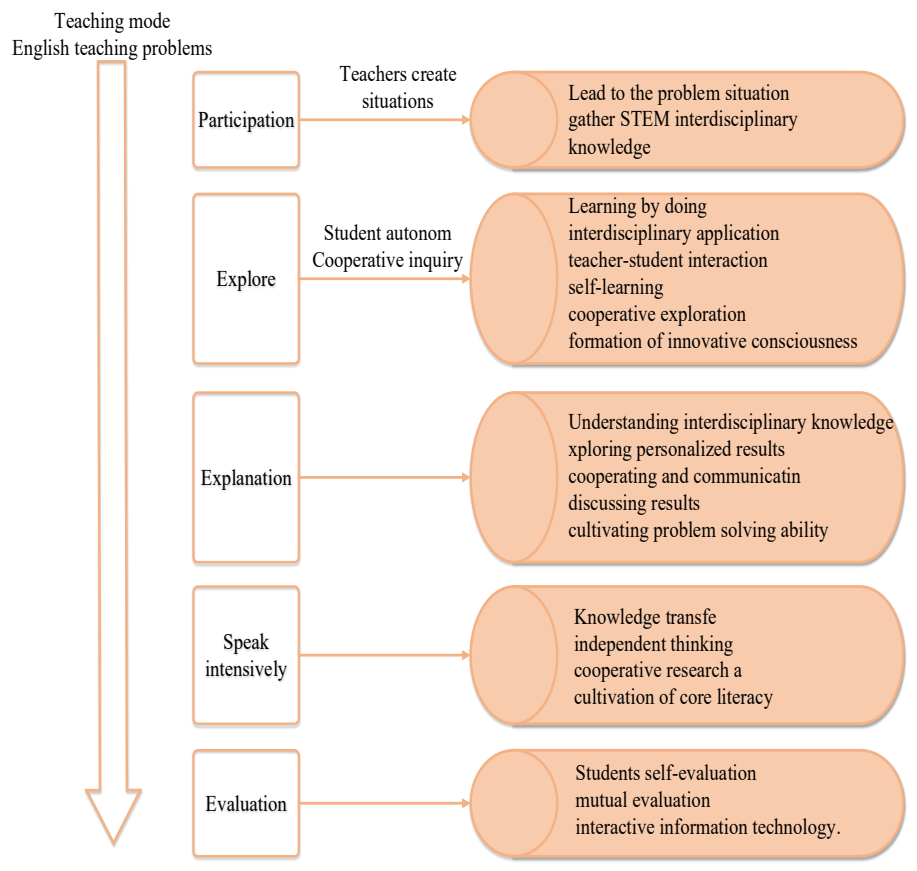

Fig. 5. Teaching process design

In this mode, students preliminarily experience STEM situation in the participation link. For college English course, before class, teachers create English-related situations in which students preliminarily contact the learning task. In class, the teacher guides students to enter the situation of animation production software, form certain questions and integrate STEM-related content to promote students to think and cause collision of old and new knowledge. Later, students enter the inquiry link. As the subject of inquiry activity, students participate in the mode of autonomous and cooperative inquiry, and establish the connection among things through observation, description, comparison, classification, exchange and discussion. The teacher is the leading role of inquiry activity, applies STEM knowledge for heuristic teaching, gives students individualized guidance and provides "scaffolding-type" support. This stage is the beginning triggering STEM innovative thinking, pays attention to cultivating students' higgh0order thinking ability and practical ability so as to promote knowledge and experience construction and skill mastery. On this basis, students show the schemes through question answering by the teacher and students, lecture, debate, and virtual demonstration after completion of inquiry - since the inquiry ques- 
tion is open, the schemes are also diversified. The teacher explains or supplements the scheme through video playing, multimedia virtual demonstration, prompt and discussion. During interpreting the concepts, the integration of subjects should be stressed to cultivate students' interdisciplinary quality, problem solving ability and innovation ability.

Then, the teacher should present the knowledge briefly and succinctly, guide students, enlighten students to solve associated new problems or new phenomena with new concepts, give proper thinking time and space for students, and guide them to summarize through participation in discussion, cooperation and exchange. The teacher further arranges inquiry tasks, guide students continuously internalize new knowledge, trains team cooperation, problem exploration and scientific innovation, and keeps improving STEM comprehensive quality. In the whole teaching process, diversified evaluation system should be conducted to enhance students' participation awareness.

\subsection{Analysis of network behavior of inquiry teaching mode based on STEM education}

The basic decision tree algorithm can be adopted to analyze the teaching mode. It is supposed that $n_{j}$ is the same size of category $c_{j}$ in dataset $X$, and the total sample size in $X$ is total. The prior probability of each category is $p\left(c_{j}\right)=n_{j} /$ total, $j=1,2, \ldots, m$.

For the dataset $X$, the expected information calculated is

$$
I\left(n_{1}, n_{2}, \ldots, n_{m}\right)=-\sum_{j=1}^{m} P\left(c_{j}\right) \log \left(P\left(c_{j}\right)\right)
$$

It is supposed that the attribute $A_{f}$ has q different values, and $X$ is divided into $\mathrm{q}$ subsets $\left\{X_{1}, X_{2}, \ldots X_{s}\right\}$. It is supposed that $n_{s}$ represents sample size in $X_{s}$, and $n_{j s}$ refers to the sample size of category $c j$ in $X_{s}$. The entropy is gained as below through dividing the dataset $X$ with the description attribute $A_{f}$.

$$
E\left(A_{f}\right)=\sum_{s=1}^{q} \frac{n_{1 s}+\ldots+n_{m s}}{\text { total }} I\left(n_{1 s}, \ldots, n_{m s}\right)
$$

Wherein,

$$
I\left(n_{1 s}, \ldots, n_{m s}\right)=-\sum_{j=1}^{m} p_{j s} \log _{2}\left(p_{j s}\right)
$$


Wherein, $p_{j s}=n_{j s} / n_{s}$ represents the proportion of data samples of category $c j$ in the subset $X_{s}, n_{s}=n_{1 s}+n_{2 s}+\ldots n_{m s}$. The smaller the entropy value in Formula (2), the higher purity the attribute for dataset division. The information gain of $A_{f}$ during dataset division is

$$
\operatorname{Gain}\left(A_{f}\right)=I\left(n_{1}, n_{2}, \ldots, n_{m}\right)-E\left(A_{f}\right)
$$

In the analysis of web-based learning behaviors, the relevance among various learning behaviors and the influence degree on learning results are known through association or decision rules to predict the possible learning effects of different learning behaviors. The algorithms related to clustering analysis can be used to analyze learning characteristics of groups with different learning behaviors. Through clustering analysis, learning generality of students in the same learning behavior group, and the academic result differences among different groups can be known. Table 1 and Table 2 show the data structure examples of relevant models established by data mining software.

Table 1. Data structure of correlation analysis modeling between students' web-based learning behavior and learning effect

\begin{tabular}{|l|l|l|}
\hline \multicolumn{1}{|c|}{ Field } & \multicolumn{1}{|c|}{ Field description } & \multicolumn{1}{c|}{ Use of column } \\
\hline $\mathrm{Xh}$ & Major key & Key column \\
\hline $\operatorname{cscs}$ & Test times (not active, general, active) & Input column \\
\hline $\operatorname{tgds}$ & Count of passing (low, general, high0 & Input column \\
\hline $\mathrm{kzcj}$ & Test results (failed, qualified, good, excellent) & Prediction column \\
\hline
\end{tabular}

Table 2. Data structure of clustering analysis modeling for web-based learning behavior

\begin{tabular}{|l|l|l|}
\hline \multicolumn{1}{|c|}{ Field } & \multicolumn{1}{c|}{ Field description } & \multicolumn{1}{c|}{ Use of column } \\
\hline $\mathrm{xh}$ & Major key & Key column \\
\hline $\operatorname{cscs}$ & Test times (type: int) & Input column \\
\hline $\operatorname{tgds}$ & Count of passing (type: int) & Input column \\
\hline $\mathrm{kzcj}$ & Test result (type: float) & Input column \\
\hline
\end{tabular}

For decision-making tree analysis of test results, modeling data structure in Table 3 as below can be considered.

Table 3. Modeling data structure of decision-making tree analysis of test results

\begin{tabular}{|l|l|l|}
\hline \multicolumn{1}{|c|}{ Field } & \multicolumn{1}{c|}{ Field description } & \multicolumn{1}{c|}{ Use of column } \\
\hline $\mathrm{Xh}$ & Major key & Key column \\
\hline $\mathrm{Cscs}$ & Score of question type 1 (A, B, C, D) & Input column \\
\hline $\mathrm{Tgds}$ & Score of question type 2 (A, B, C, D) & Input column \\
\hline Kzcj & Score of question type 3 (A, B, C, D) & Input column \\
\hline$\ldots$ & $\ldots$ & Input column \\
\hline Total scores & Total score (A, B, C, D) & Prediction column \\
\hline
\end{tabular}


The purpose of data mining is to discover the knowledge and rules hidden in the data, and solve or improve relevant problems by applying the minding results. For example, the results of correlation analysis and clustering analysis in the above example can be used to improve the following shortcomings in web-based teaching:

- Correlation analysis can help the teacher recommend learning behavior, learning resource and learning tasks contributing to improving their learning effect. Learning ability and web-based learning efficiency can be improved through recommending successful learning experience and guiding students to formulate effective learning strategy.

- Students' feature classification model is set up through clustering analysis, which contributes to discovering students' potential learning problems, and helps students correct learning behavior. Meanwhile, it contributes to students to check their shortcomings and determine the striving direction by contrasting the classification model.

\section{Teaching Example and Effect}

\subsection{Teaching example}

To establish college English teaching mode based in STEM educational concept, the design should be performed from three aspects including classroom preparation stage, classroom teaching implementation stage and evaluation stage on the basis of the above modeling process. The teaching mode designed in this study is shown in Fig.6. It can be seen from the figure that, the preparation stage mainly involves learning situation analysis of students' English learning and teacher arrangement. In this stage, the teacher should mainly understand students' cognitive level, learning style and English foundation, etc., prepare STEM knowledge and content associated with teaching content, like historical background, scientific and technological level, and social class distribution features. In the implementation stage, the software for animation courseware making and multimedia player should be prepared. The analysis of event development process under the legal background described in the event that the figure encounters is proposed for students in the form of task, and the reason and process of conflicts are analyzed. The evaluation stage penetrates the task solving process. Students are grouped for discussion, summarization and expression, form the learning reports, and carry out mutual evaluation among teams and inter-group mutual evaluation to form the multi-form and multi-perspective evaluation results. In the end, the final evaluation forms as the learning effect evaluation content for the students to learn the chapter. 


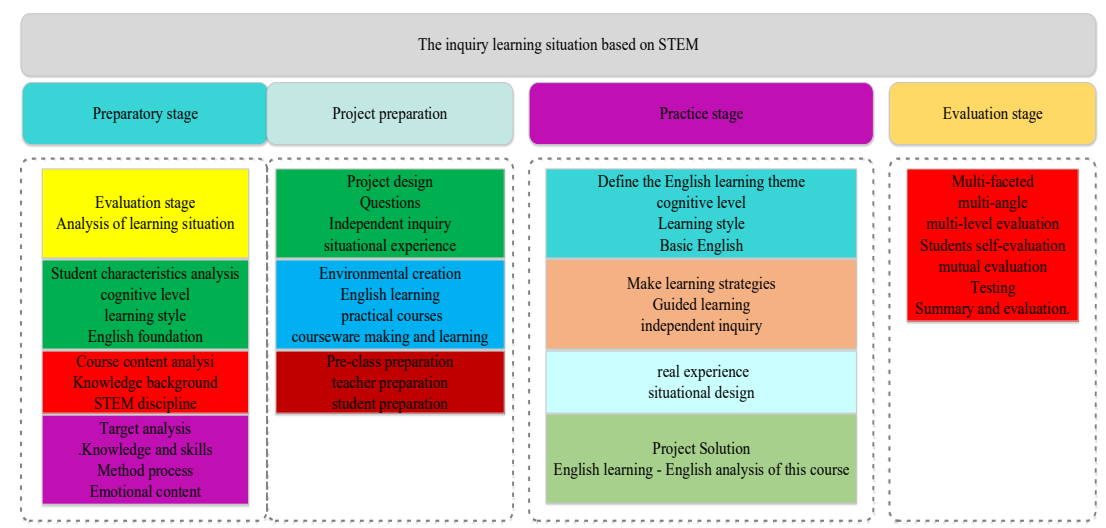

Fig. 6. Classroom Inquiry teaching mode of college English based in STEM educational concept

The teaching mode of the course was investigated in this study. The author distributed the animation production software to students and let them learn the software in groups. The teaching process involves English material making by animation production software. Besides, laws and class background material of western countries are deeply explored according to the teaching content. The learning report with rich contents forms by animation making patent. Fig. 7 shows the video screenshot produced by the student group during introducing relevant background.

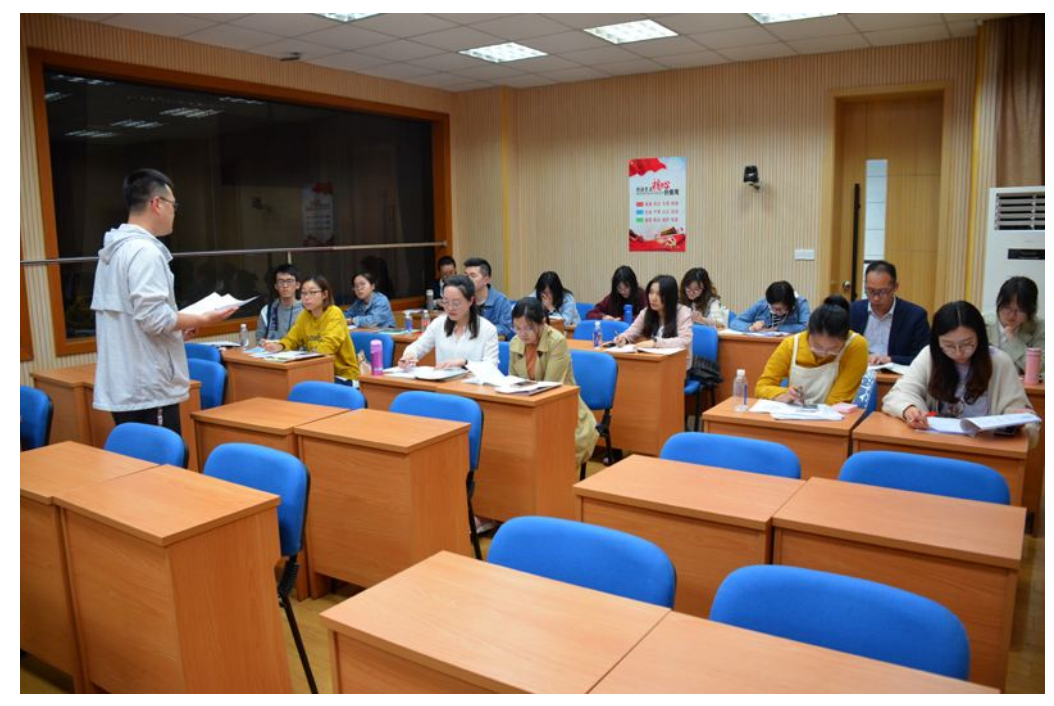

Fig. 7. STEM multidisciplinary knowledge screenshot involved in inquiry learning of student group 


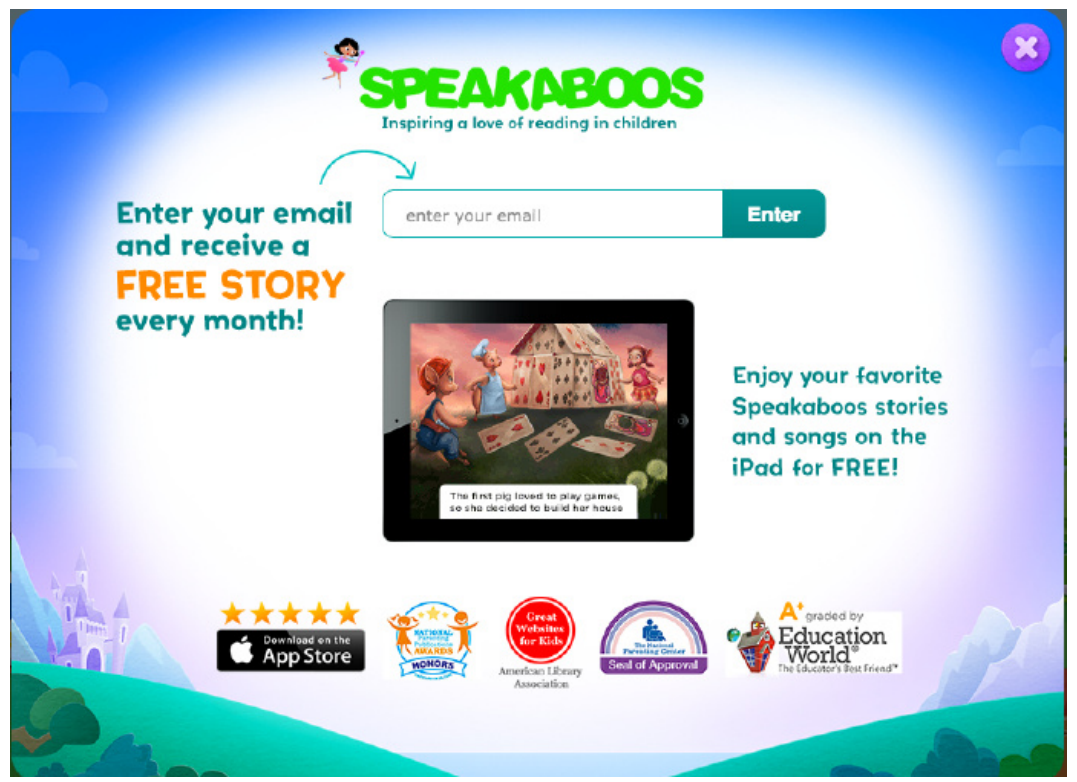

Fig. 8. STEM multidisciplinary English teaching software screenshot I of inquiry learning

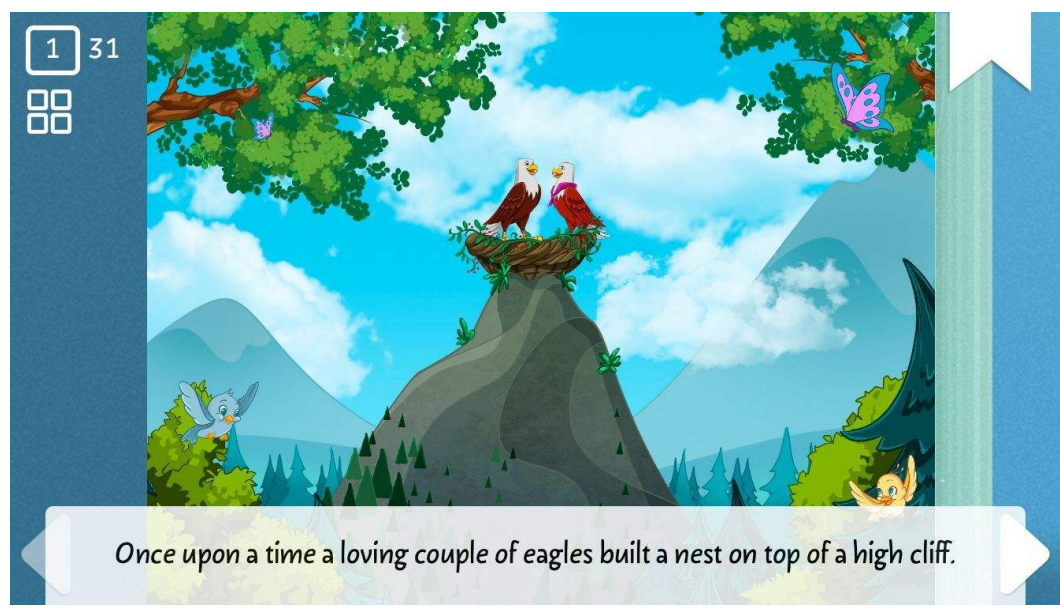

Fig. 9. STEM multidisciplinary English teaching software screenshot II of inquiry learning

Fig.8 and Fig.9 display the application link of STEM multidisciplinary English teaching software of inquiry learning which combines inquiry learning in this teaching experiment. In the teaching process, the teacher adopts Speakaboos software. The largest product feature of Speakaboos is inquiry teaching mode. In the reading process, students can autonomously guide story direction and even change the story ending through touching ipad and other equipment. The largest benefit is that students can give play to their initiative, and take more active part in knowledge exploration process. Except audio books, Speakaboos also provides children's folks, cradlesongs 
and other music resources. To our surprise, all reading materials in the App are recorded by celebrities, such as the famous actor Kevin Bacon, talk show host Kelly Ripa, and the rapper Nick Cannon. Moreover, Speakboos also covers Flash game and electronic greeting card, and all color pages can be printed in the form of PDF. Students can set up a special account by themselves, and the teacher can limit the type of contents they can access.

\subsection{Teaching effect}

In this study, 52 students in Grade 1 were chosen as the experimental class to investigate the teaching mode. The experimental period is the first semester of 2018. At the same time, another parallel class (48 students) in the same grade was selected as the control class for which traditional PPT teaching mode was used. After the semester ended, the teaching effects of experimental class and control class were compared. The author adopted the self-made questionnaire to conduct statistics of students' satisfaction with College English by using the inquiry learning mode based on STEM educational concept, and investigated the teaching effect evaluation of experimental class for the mode proposed. The questionnaire designed the effect evaluation from 8 aspects, and visual analogue scale was applied to score the 8 evaluation items. The analysis was based on the satisfaction of students' various abilities. The analysis results are shown in Table 1. Compared with traditional teaching mode, the score differences of the inquiry teaching mode based on STEM theory had statistical significance $(\mathrm{p}<0.01)$, indicating that this teaching mode can significantly improve students' English learning effect and improve their comprehensive abilities.

Table 4 shows teaching effect evaluation of experimental class and control class for virtual reality teaching system.

Table 4. Attribute of teaching mode accepted by experimental class and control class

\begin{tabular}{|l|c|c|c|c|}
\hline \multicolumn{1}{|c|}{ Item } & $\begin{array}{c}\text { Experimental class } \\
(\mathbf{n = 5 2 )}\end{array}$ & $\begin{array}{c}\text { Parallel class } \\
(\mathbf{n = 4 8 )}\end{array}$ & $\boldsymbol{t}$ & $\boldsymbol{P}$ \\
\hline Promoting English learning interest & 8.80 & 7.76 & 4.70 & $<0.001$ \\
\hline Interest in English learning content & 9.08 & 7.75 & 5.81 & $<0.001$ \\
\hline Problem analysis and solving & 8.92 & 7.77 & 5.67 & $<0.001$ \\
\hline Innovative thinking establishment & 8.80 & 7.81 & 4.40 & $<0.001$ \\
\hline Communication and exchange & 9.30 & 8.32 & 5.30 & $<0.001$ \\
\hline Teamwork ability & 9.51 & 8.41 & 5.95 & $<0.001$ \\
\hline Social practice & 8.92 & 7.00 & 7.28 & $<0.001$ \\
\hline Emotional experience & 9.12 & 7.81 & 6.13 & $<0.001$ \\
\hline
\end{tabular}

From the comparison of experimental group and control group, it can be seen that the inquiry learning mode based on STEM theory is accepted by students, and its satisfaction evaluation is obviously higher than that of control class, fully demonstrating that the inquiry teaching mode proposed in this study is suitable for College English teaching, with the better learning effect. According to Table 1, the inquiry teaching mode based on STEM theory can improve students' interest in learning English through effective technical means. Students' English learning interest is enhanced by 
the expansion and integration of STEM multidisciplinary knowledge. Thus, students' English application ability and specialty literacy are promoted. The inquiry learning mode can give full play to students' learning initiative and autonomy so that students can gain problem solving ability through teamwork in the learning process, enhance their ability to overall apply English, focus on sociality of relevant disciplinary knowledge and experience response emotions under various events and situations. This teaching mode cannot just let students link the knowledge learned in classroom with the real world, society and emotion and thus motivate their learning interest, but also let the relations between students and teachers become more harmonious in interactions and improve the teaching effect. In one word, the teaching mode in this study can significantly improve students' learning effect and contributes to cultivating students' comprehensive qualities and problem-solving ability.

\section{Conclusion}

In this study, STEM educational theory and inquiry teaching method were combined, and animation production software tool was adopted to build the college English teaching mode, besides, the practical study was conducted. Then, the questionnaire was used to understand students' evaluation for the teaching effect of this teaching mode. Finally, the following conclusions were gained:

- The inquiry learning mode based on STEM theory is accepted by students, and can obviously improve students' interest in English study. The teaching mode in this study can integrate relevant knowledge of STEM subjects, promotes students' English learning interest and enhance their English application ability and professional quality.

- The inquiry learning mode can give full play to students' learning initiative and autonomy so that students can gain problem solving ability through teamwork in the learning process, enhance their ability to overall apply English, focus on sociality of relevant disciplinary knowledge and experience response emotions under various events and situations.

- The teaching mode can enhance teacher-student interactions and improve the teaching effect.

Although the teaching mode can satisfy students' learning demand in language courses, it is also necessary to notice that language study requires lots of basic exercises and imitation trainings in order to gain the real learning ability. This teaching mode should be scientifically planned by combining language study requirements and features, which will be a feasible development direction of language course teaching reform. 


\section{$6 \quad$ References}

[1] Ozmen, K.S. Fostering Nonverbal Immediacy and Teacher Identity through an Acting Course in English Teacher Education. Australian Journal of Teacher Education, 2010, vol. 35(6), pp. 1-23. https://doi.org/10.14221/ajte.2010v35n6.1

[2] Kramer, D. Universities seek culture change for improved STEM teachin]. Physics Today, 2011, vol. 64(11), pp. 22-25. https://doi.org/10.1063/pt.3.1324

[3] Ke, K.J. Challenges in STEM Teaching: Implication for Preservice and Inservice Teacher Education Program. Theory Into Practice, 2014, vol. 53(1), pp. 18-24. https://doi.org/10. 1080/00405841.2014.862116

[4] Kelley, T.R., Knowles, J.G. A conceptual framework for integrated STEM education[J]. International Journal of Stem Education, 2016, vol. 3(1), pp. 11. https://doi.org/10.1186/ $\underline{\text { s40594-016-0046-Z }}$

[5] Singer, S.R., Nielsen, N.R., Schweingruber, A.H.A., et al. Discipline-Based Education Research: Understanding and Improving Learning in Undergraduate Science and Engineering. Journal of Engineering Education, 2013, vol. 102(4), pp. 468-471. https://doi.org/10. $\underline{1002 / j e e .20030}$

[6] Phillips, R. L. A comparison of college readiness among students enrolled in Texas science, technology, engineering, and mathematics academies and traditional comprehensive high schools. Tarleton State University, 2013.

[7] Cavlazoglu, B., Stuessy, C. Changes in science teachers' conceptions and connections of STEM concepts and earthquake engineering. Journal of Educational Research, 2017, vol. 110(3), pp. 1-16. https://doi.org/10.1080/00220671.2016.1273176

[8] Xie, L., Li, C.M. Research and Practice of Integrating Physics Course into STEM Education Concept. Physics Teacher, 2017, vol. 38(4), pp. 2-4.

[9] Zhao, C.L., Shen, J.J., Jiang, Z.H. A Study on the Construction of an Instructional Model Integrating Maker Education and STEM Education. E-education Research, 2018, vol. 39(9), pp. 83-89.

[10] Zhao, X.L., Xu, L. STEM Education: Five Major Controversies and Further Discussion. China Educational Technology, 2016, vol. 37(10), pp. 62-65.

[11] Doering, A., Beach, R., O'Brien, D. Infusing Multimodal Tools and Digital Literacies into an English Education Program. English Education, 2007, vol. 40(1), pp. 41-60.

[12] Williams, P.J. STEM Education: Proceed with Caution. Design \& Technology Education, 2011, vol. 16(1), pp. 26-35.

\section{$7 \quad$ Author}

Lian Zhai is an associate professor in the Sichuan Vocational and Technical College, Suining, China (lydia19811@163.com).

Article submitted 2019-07-05. Resubmitted 2019-07-15. Final acceptance 2019-07-16. Final version published as submitted by the authors. 